\title{
The role of telomeres and telomerase in hematologic malignancies and hematopoietic stem cell transplantation
}

\author{
Limengmeng Wang ${ }^{1 \dagger}$, Haowen Xiao ${ }^{1,2+}$, Xing Zhang ${ }^{1}$, Chong Wang ${ }^{3}$ and He Huang ${ }^{1 *}$
}

\begin{abstract}
Telomeres are specific nucleoprotein structures at the ends of eukaryotic chromosomes. Telomeres and telomere-associated proteins maintain genome stability by protecting the ends of chromosomes from fusion and degradation. In normal somatic cells, the length of the telomeres gradually becomes shortened with cell division. In tumor cells, the shortening of telomeres length is accelerated under the increased proliferation pressure. However, it will be maintained at an extremely short length as the result of activation of telomerase. Significantly shortened telomeres, activation of telomerase, and altered expression of telomere-associated proteins are common features of various hematologic malignancies and are related with progression or chemotherapy resistance in these diseases. In patients who have received hematopoietic stem cell transplantation (HSCT), the telomere length and the telomerase activity of the engrafted donor cells have a significant influence on HSCT outcomes. Transplantation-related factors should be taken into consideration because of their impacts on telomere homeostasis. As activation of telomerase is widespread in tumor cells, it has been employed as a target point in the treatment of neoplastic hematologic disorders. In this review, the characteristics and roles of telomeres and telomerase both in hematologic malignancies and in HSCT will be summarized. The current status of telomerase-targeted therapies utilized in the treatment of hematologic malignancies will also be reviewed.
\end{abstract}

Keywords: Telomere, Telomerase, Shelterin, Hematologic malignancies, Hematopoietic stem cell transplantation, Target therapy

\section{Introduction}

The telomeres are specific nucleoprotein structures at the ends of eukaryotic chromosomes which maintain genome stability by protecting chromosomes from end fusion and degradation. Human telomeres are composed of $10-15 \mathrm{~kb}$ of 5'-TTAGGG-3' DNA sequence repeats and a telomere-associated protein complex, shelterin (reviewed by Blackburn) [1]. The end of each telomere consists of a t-loop structure formed by strand invasion of the $3^{\prime}$ single strand overhang into the double-stranded telomeric DNA and then stabilized by shelterin [2].

In most somatic cells, telomeres gradually become shortened (20-59 bp/year) because of the end-replication

\footnotetext{
* Correspondence: hehuang.zju@gmail.com

${ }^{\dagger}$ Equal contributors

'Bone Marrow Transplantation Center, The First Affiliated Hospital, Zhejiang University, School of Medicine, No. 79 Qingchun Rd, Hangzhou 310003,

Zhejiang Province, P R China

Full list of author information is available at the end of the article
}

problem during cell division [3,4]. Once its length reaches a critical limitation, the telomere is unable to assemble the $\mathrm{t}$-loop structure and the chromosome becomes uncapped. At this point the DNA damage response and replicative senescence will be triggered through the ataxia telangiectasia-mutated gene (ATM) or the ataxia telangiectasia and Rad3 (ATR) -related checkpoint pathway [5]. However, cells in which cell cycle checkpoint proteins have been inactivated are able to continue division and continue losing telomeric sequences until they reach a crisis stage in which p53-dependent apoptosis is triggered. Cancer cells have to go through the crisis stage to maintain their telomeres and achieve immortality. In the majority of cancer cells ( $80 \%$ to $90 \%$ ), telomerase has been activated to maintain telomere length [6], while a subset of cancer cells elongate telomeres through telomerase-independent mechanisms named alternative lengthening of telomeres (ALT) [7]. 
Telomerase is a reverse transcriptase which maintains telomere length by adding nucleotides to the singlestranded (ss) DNA of the telomere during cell division [8]. Telomerase consists of a protein component (hTERT) and an RNA template component (hTERC). hTERT is the catalytic subunit of telomerase which limits its reverse transcriptase activity. hTERC consists of an 11 nucleotide sequence (5' -CUAACCCUAAC-3') which is complementary to the telomere sequence (TTAGGG)n [9]. Telomerase is recruited to the telomere via its interaction with shelterin.

Shelterin is a protein complex which consists of 6 telomere-associated proteins: telomeric repeat-binding factors 1 and 2 (TRF1 and TRF2), TRF1-interacting nuclear factor 2 (TIN2), protection of telomeres (POT1), POT1 and TIN2-interacting protein 1 (TPP1), and TRF2interacting protein 1 (Rap1) (Figure 1). Shelterin protects the telomere from being recognized as a double-strand break in the DNA sequence which would lead to activation of the DNA damage response and repair process (reviewed by de Lange) [10]. Shelterin is anchored to the chromosomal end by the double-strand (ds) DNA binding proteins TRF1 and TRF2, the ss DNA binding protein POT1, and Rap1 which binds DNA at the ds-ss junction of the telomere [11]. TRF1 and TRF2 bind TIN2 simultaneously to form two separate complexes $[12,13]$. The binding between TRF1/TRF2 and TIN2 protects TRF1/TRF2 from degradation by tankyrase and prevents their inappropriate localization [13].

POT1 and TRF2 interact with each other and protect the telomeres from the DNA damage response triggered by the ATR and ATM pathways independently $[14,15]$. POT1-deleted mice show increased p53-dependent apoptosis, as well as elevated DNA damage response and chromosomal fusions [16]. TPP1 forms a heterodimer with POT1 and acts as the bridge between the TRF1 complex and telomerase $[17,18]$.

\section{Telomeres and telomerase in hematologic malignancies}

Acute leukemia (AL)

$\mathrm{AL}$ is characterized by uncontrolled proliferation of myeloid precursor cells (acute myeloid leukemia, AML) or lymphoblast cells (acute lymphoblastic leukemia, ALL). Shortened telomere length is observed in patients with AL and is associated with chromosome instability. Capraro et al. reported that AL patients with an aberrant karyotype have significantly shorter telomere length than patients with a normal karyotype, and those patients with multiple aberrations possess the shortest telomeres. They also compared telomere length and telomerase activity in different subtypes of AL cells. They found that B-ALL cells had the shortest telomeres and the highest level of telomerase activity among all the subtypes of AL. Leukemia cells with abnormal karyotypes exhibited shorter telomeres than those with a normal karyotype (4.5 kb vs. $9.14 \mathrm{~kb}$ in ALL, $4.33 \mathrm{~kb}$ vs. $7.06 \mathrm{~kb}$ in AML) [19]. The order of telomerase activity is ranked B-ALL > AML > T-ALL.

The hTERT component of telomerase possesses many alternatively-spliced forms in which only the full-length transcript $(+\alpha+\beta)$ can be translated into a properly active enzyme. B-ALL cells exhibit the highest proportion of the full-length active product, in line with the trend in telomerase activity. Among all French-American-British (FAB) subtypes of AML, M0 and M3 have the lowest telomerase activity [19]. The telomerase activity of ALL cells has been reported to be higher in male patients with than in female patients. This may be due to the negative regulatory function of estrogen on telomerase [20].

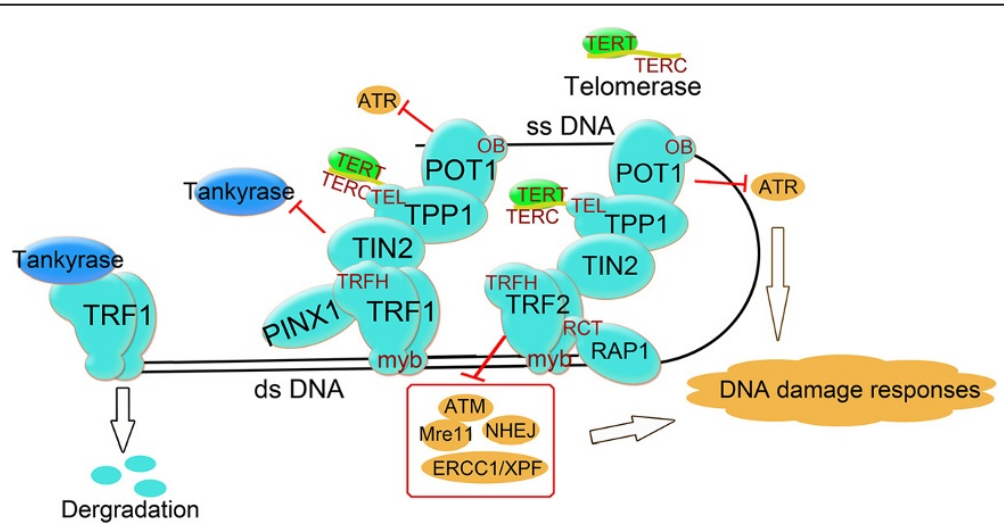

Figure 1 The structure of shelterin. TRF1 and TRF2 bind to double strand (ds) DNA and form two separate complexes with other shelterin proteins. POT1 binds to single strand (ss) DNA while RAP1 binds to DNA at the ds-ss joint. PINX1 is a TRF1 binding protein. TIN2 binds TRF1 and TRF2 spontaneously and protects TRF1 from being degraded by tankyrase. TPP1 and POT1 form a heterodimer. TPP1 links TIN2 and POT1/TPP1 and recruits telomerase to the shelterin complex. 
Shortened telomere length and increased telomerase activity are associated with reduced response to chemotherapy, faster disease progression and poor prognosis in patients with AL. AML patients in the late stage of the disease have shorter telomere lengths and higher telomerase activity than those in the early stages. Relapsed AML patients have the shortest telomere length and highest telomerase activity [21,22]. Asfour et al. reported that apoptosis of the leukemic blasts was blocked by telomerase in ALL patients, resulting in an increased tumor burden, faster disease progression and shortened survival [20]. Telomerase activities in ALL patients correlated to the enzyme concentration of lactate dehydrogenase (LDH), which is an adverse prognostic factor in ALL patients [20].

Altered expression of shelterin proteins has also been reported in de novo acute leukemic cells. Shi et al. reported that the expression of TRF1, which is a negative regulator of telomerase activity, was lower in patients with AL than in normal volunteers [23]. Ohyashiki et al. reported that patients with high hTERT expression or longer telomere length tended to have higher levels of TRF1 expression [24]. Capraro et al. compared the expression of shelterin proteins between different subtypes of AL. They found that TRF1 expression was reduced in AL and was lowest in AML patients. Meanwhile TRF2 expression was increased in AL and was highest in B-ALL patients, especially in B-ALL patients with abnormal karyotype. Expression of both TPP1 and RAP1 was increased in AL and was highest in T-ALL patients [19]. After chemotherapy, the TRF1 expression level increased in patients achieving complete remission (CR) but not in those patients in whom CR was not achieved [23]. When the acute promyelocytic leukemia (APL) cell line HL-60 was induced to differentiate into mature cells, telomerase activity was reduced and the expression of TRF1, TRF2 and TIN2 was increased [25].

\section{Chronic lymphocytic leukemia (CLL)}

CLL is characterized by an abnormal expansion of mature B lymphocytes. Reliable prognostic factors are crucial for choosing therapeutic strategies in CLL patients and in predicting the outcome (reviewed by Kipps) [26]. Shorter telomeres, increased telomerase activity and altered expression of shelterin proteins are all observed in CLL patients. Patients with high-risk genomic aberrations, 11q or $17 \mathrm{p}$ deletions, undergo more severe telomere attrition due to the loss of ATM or p53, which are necessary to trigger p53-dependent apoptosis and the DNA damage response [27]. CLL patients with ATM mutations all display extreme telomere shortening independent of disease stage [28]. Patients with the chromosome aberration of a 17p deletion also show up-regulated c-myc which is a positive regulator of hTERT [29]. Functional assessment of the
TP53 pathway was recently proposed as a method to precisely identify high risk CLL [30]. More evidence will be necessary to confirm the connection between telomere dysregulation and dysfunction of the TP53 pathway in CLL patients.

The observed shortening of telomere length in CLL patients was in line with other classical biological factors of CLL, including unmutated immunoglobulin variable region genes (UM-IGVH), CD38 and ZAP-70 positivity ( $>30 \%)$ and short ( $<6$ months) lymphocyte doubling time [29]. Sellmann et al. reported a linear correlation between the frequency of IGHV gene mutations and the length of the telomeres [31]. CLL patients with shorter telomere length experienced worse clinical outcomes including shorter progression-free survival (PFS) and overall survival (OS) $[29,32]$. Thus telomere length was indicated as a negative prognostic factor and a threshold of $-4.2 \mathrm{~kb}$ was suggested to be a predictive separation in Sellmann's study [31].

Shelterin alterations were also identified in CLL patients and were found to be involved in telomere instability. The expression levels of TRF1, RAP1 and POT1 were all reported to be reduced in B-CLL cells, while the expression of TPP1 was increased [33]. In contrast, the expression of TPP1 and TIN2 were reported to be down-regulated in newly diagnosed Binet stage A CLL patients in another study [34]. Telomere dysfunction caused by a POT1encoding gene mutation was recently identified in CLL patients. The frequency of POT1 mutation was $3.5 \%$ in CLL patients and reached 9\% in CLL patients without IGHV mutations [35].

\section{Chronic myelocytic leukemia (CML)}

CML is a myeloproliferative neoplasm characterized by the presence of $B C R / A B L$ fusion genes which encode the $\mathrm{Bcr}-\mathrm{Abl}$ fusion protein. The tyrosine kinase activity of the Bcr-Abl fusion protein induces oxidative damage and telomere shortening by generating reactive oxygen species [36]. A shorter average telomere length was found in leukemic cells of CML patients compared with white blood cells of age-matched healthy individuals or BCR/ ABL-negative $\mathrm{T}$ lymphocytes from the same patients [37]. Furthermore, telomere shortening was accelerated as the disease progressed from the chronic phase $(\mathrm{CP})$ to the blastic phase (BP), with a rate approximately 10 times that in normal controls. Patients with a high-risk Hasford score at diagnosis exhibited significantly greater telomere loss than patients with a low-risk score, while patients with intermediate risk showed an intermediate telomere loss rate [38]. Average telomere length increased when patients achieved complete cytogenetic remission (CCR) under treatment with Imatinib Mesylate (IM) owing to the hematopoietic reconstruction of BCR/ABL negative cells. In contrast, patients who did not respond to IM exhibited 
a decrease in telomere length consistent with rapid cell division [38]. Braig et al. utilized bone marrow cells of telomerase knockout mice to establish a CML-like cell culture. They demonstrated the presence of shorted telomeres with an increase in the secretion of proinflammatory cytokines and growth factors associated with proliferation control in telomerase negative CML-like cells. Their work indicated that a telomerase-targeting strategy could induce senescence in CML-like cells and alleviate the tumor promoting/progressing effect of BCR-ABL [39]. Bakalova et al. demonstrated cross-talk between $\mathrm{Bcr}-\mathrm{Abl} / \mathrm{c}-\mathrm{Abl}$ tyrosine kinase and telomerase in $\mathrm{CML} / \mathrm{ALL}$ cells. Antisense inhibition of Bcr-Abl/c-Abl proteins was able to reactivate telomerase to maintain cell proliferation. Therefore the combination of TKI and telomerase targeting may be a promising strategy in CML treatment [40].

Individual telomere lengths have been determined in CML patients. Pronounced shortening of telomeres has been found on Yp, Yq, 1q, 5q, 9q, 8p, 21p and 21q. Genomic instability caused by high telomere attrition rates on the Y chromosome and on chromosome 21 might account for secondary chromosomal abnormalities during disease progression. An interesting finding was that telomere length in some individual chromosome ends was well maintained or even elongated. Some longtelomere chromosome arms (7q, 11p, 15p, and 18p) recurrently and specifically showed up in CML samples compared with healthy controls. Long telomeres on key chromosomes may contribute to a cell proliferation advantage during clonal selection in the early stage of CML ontogenesis [41,42].

The circular extra-chromosomal telomeric repeat (ECTR), one of the ALT hallmarks, was used to define ALT activation in CML patients in a recent study. In this study, $27 \%$ of CML patients in CP were reported to exhibit both high ALT activity and telomerase activities. As telomerase activity increases with disease progression, the dominating telomere maintenance mechanism might transition from ALT to telomerase [43].

Altered expression of shelterin proteins was also reported in progressing CML patients. Campbell et al. reported that expression levels of TRF1 and TRF2 were increased in CML patients in the $\mathrm{CP}$ and in the accelerated phase (AP) but reduced to a level comparable to normal controls in the majority of patients in the BP. Increased expression of TRF1 may thus induce telomere shortening in CML in both the CP and AP [44]. High levels of TRF2 and tankyrase might contribute to the delay in senescence signaling triggered by the critically shortened telomeres and the consequent maintenance of telomere length. When K562 cells were treated with Anti-Bcr-Abl mRNA, decreased expression of TRF1 and TIN2 were observed [40].

\section{Myelodysplastic syndromes (MDS)}

MDS are a group of disorders characterized by dysplastic features in the hematopoietic cells with the tendency to progress into acute leukemia [45]. By reason of the heterogeneity of the diseases, results of telomere length of MDS patients are not consistent. Recently, shortened telomeres have been reported in isolated peripheral blood leukocytes, CD15+ myeloid cells and CD19+ lymphocytes of MDS patients [46]. Although the MDS clone originates within the myeloid compartment, abolishment of T-lymphocytes differentiation and loss of naïve T-cells are consequences of hTERT deficiency [47]. However, telomere lengths in marrow stromal cells are reported to be stabilized well [48]. The telomere lengths of individual chromosome arms was measured by Lange et al., who found markedly longer telomeres in several chromosome arms in patients with an isolated monosomy 7 compared with patients with a normal karyotype or a complex karyotype [49]. The mechanism(s) involved in the stabilization or elongation of telomeres in patients with monosomy 7 still requires future exploration.

Patients with telomere shortening at the time of diagnosis showed a high frequency of complex chromosome abnormalities, faster disease evolution and shorter survival time [50,51]. Sieglová et al. compared the telomere length of MDS patients with different FAB subtypes. Telomere length in the early phases of MDS (RA and RARS) was longer compared to that in advanced forms of MDS (RAEB + RAEB-T) and was shortest in secondary AML from MDS. A significant negative correlation between telomere length in bone marrow cells of MDS patients and the International Prognostic Score System (IPSS) score was observed [52]. In order to stabilize telomere length, hTERT expression level and telomerase activity were increased in MDS patients in the more advanced stages [53]. Thus shortened telomeres and increased telomerase activity could be regarded as prognostic factors for MDS patients. In a recent study, three-dimensional quantitative FISH of telomeres was carried out on nuclei from bone marrow samples of MDS and AML patients. Three-dimensional (3D) telomeric profiles which were determined based on the nuclear telomeric architecture, telomere numbers, the presence of telomere aggregates, telomere signal intensities, nuclear volumes, and nuclear telomere distribution, confirmed a dynamic and evolutionary process of telomere dysfunction during the transformation of MDS to AML [54].

\section{Telomeres and telomerase in hematopoietic stem cell transplantation (HSCT)}

HSCT is a potential curative therapy for many hematologic disorders and immunodeficiency diseases. The self-renewal capacity of hematopoietic stem cells (HSCs) is essential for reconstitution of the hematopoietic system. The 
proliferative potential of HSCs decreases with differentiation and age in line with the shortening of telomeres and increased telomerase activities in these cells. Mean telomere length is shorter in HSCs purified from adult bone marrow than from fetal liver or umbilical cord blood [55]. Telomerase activity is higher in HSCs during the late development stage than in non-expanding HSCs [56].

hTERT-deleted mice have been used as a telomerasedeficient model for the study of telomerase function in the hematopoietic system [57-59]. Sekulovic et al. reported the loss of a $10 \mathrm{~kb}$ length of the telomere of leukocytes generated from hTERT knockout HSCs after 6 days of in vitro expansion and 3 months of regeneration in secondary-transplanted recipient mice [57]. Telomere dysfunction impaired mesenchymal progenitor cell function, reducing the capacity of bone marrow stromal cells for maintaining functional HSCs. When wild-type HSCs were transplanted into TERC-knockout recipient mice, accelerated myelopoiesis and impaired B-cell development occurred [59].

Patients who received autologous or allogeneic HSCT (auto-HSCT or allo-HSCT) experienced more severe erosion of telomere length in their blood cells under massive differentiation pressure compared with their donors. Akiyama et al. reported that the telomeres of transplanted cells became shortened by up to $1.9 \mathrm{~kb}$ in auto-HSCT recipients over an observation period of 5.3 years, the same frequency of telomere erosion as would occur over 15-20 years in normal individuals. Telomere erosions of up to $2.1 \mathrm{~kb}$ were observed in patients who received allo-HSCT [60]. Baerlocher et al. evaluated 44 long-term survivors after allo-HSCT with a median follow-up of 17.5 years. Significantly shortened telomere length was observed in all blood cells lineages, including granulocytes, naive/ memory $\mathrm{T}$ cells, B cells and natural killer/natural killer $\mathrm{T}$ cells in the recipients compared with that in their donors [61]. The rate of telomere shortening in recipients is highest in the first year after HSCT and then slows down to a rate similar to that of their donor and of healthy controls [62]. Telomere shortening in patients who received allo-HSCT seems to be more sensitive to the influence of ageing than auto-HSCT. A correlation between donor age and telomere shortening rate has been found in alloHSCT but not in auto-HSCT recipients [60].

In allo-HSCT, more severe telomere shortening is associated with elderly donors, female donors and the development of chronic graft-versus-host disease (cGVHD) $[60,61]$. The accelerated telomere shortening of transplanted female donor cells may be a consequence of the deficiency of estrogen-upregulated telomerase activity after transplantation [63]. Patients who develop cGVHD also show more severe telomere attrition, probably due to chronic inflammation and oxidative stress. In contrast, development of acute GVHD (aGVHD) has no significant impact on telomere length in recipients [61]. CD4+ CD25 + Foxp3+ regulatory $\mathrm{T}$ cells (Treg) constitute a lymphocyte subgroup responsible for the control of cGVHD. Patients with telomerase deficiency in Treg have impaired proliferative capacity of these cells and consequently a higher incidence of moderate or severe cGVHD [64].

Treatments involved in the HSCT procedure could also have an impact on the telomere homeostasis of engrafted HSCs and may eventually influence the outcomes of recipients (Figure 2). In patients who received auto-HSCT, pre-transplantation chemotherapy has a significant influence on the telomere length of transplanted cells. Telomere length is negatively related to the number of courses of cytoreductive therapy received by patients [60]. Ricca et al. compared telomere length in peripheral blood progenitor cells (PBSCs) collected after two tightly-spaced high-dose (hd) chemotherapy courses. Telomere length was significantly shorter in PBSCs collected after the second course (hd-Ara-C) compared to that collected after the first course (hd-CY) [65]. This difference in telomere length of collected PBSCs determines the telomere length of the hematopoietic cells after auto-HSCT. In another study patients transplanted with PBSCs from the second collection had significantly shorter telomeres than those who received PBSCs from the first collection [66].

Donors' HSCs with longer telomeres could offer a replicative advantage and lead to faster granulocyte recovery in the recipient after HSCT. In contrast, patients with shorter telomere lengths after HSCT took a longer period to reach neutrophil recovery and had a greater risk of developing hematopoietic disorders [67]. Accelerated telomere shortening and consequent chromosomal instability are independently associated with the development of therapy-related myelodysplasia or acute myelogenous leukemia (t-MDS/AML) after auto-HSCT in patients with Hodgkin's lymphoma or non-Hodgkin's lymphoma. In patients who developed t-MDS/AML, reduced proliferative capacity of HSCs contributed to decreased generation of committed progenitors [68].

The telomere length of hematopoietic cells in the recipient before HSCT, which represents the inner environment of host, is another factor impacting the outcome of transplantation. Peffault et al. reported that treatment-related mortality was inversely correlated with age-adjusted recipients' pre-transplantation telomere length in their lymphocytes (hazard ratio, 0.4) in patients who received allo-HSCT, especially in patients with advanced stage disease [69].

\section{Telomerase-targeting therapies}

Since the increased expression of hTERT and activation of telomerase are universally involved in oncogenesis and the progression of hematopoietic malignancies, telomerase 


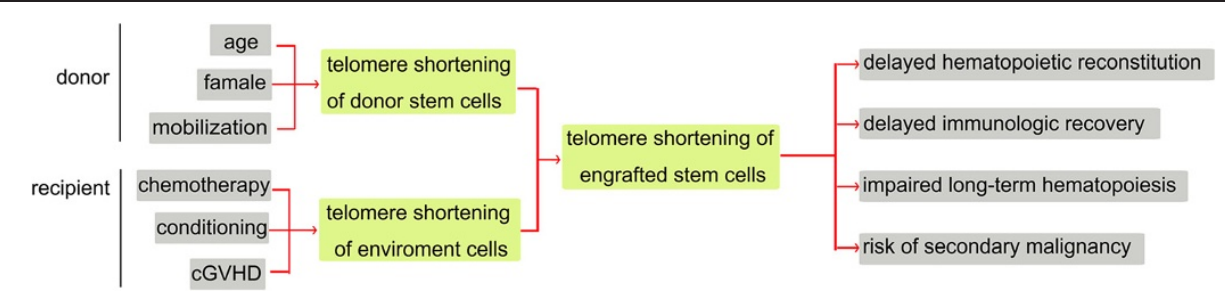

Figure 2 Factors affecting telomere length and recipient outcomes in hematopoietic stem cell transplantation. Mobilization, older donors, and female donors are related to shortened telomeres in donor stem cells. Chemotherapy and conditioning courses before hematopoietic stem cell transplantation (HSCT) could also accelerate telomere shortening in host cells. The telomere length (TL) of grafted stem cells is mainly determined by the pretransplantation TL of donor cells, but is also affected by the host environment and by the occurrence of chronic graft versus host disease (cGVHD). The TL of engrafted donor stem cells is important for the continuous and stable reconstitution of the hematopoietic system.

inhibition could be an effective antineoplastic strategy for therapy (Figure 3).

\section{Immunotherapies}

Telomerase-based immunotherapies utilize telomeraseassociated antigens to elicit CD4+ and CD8+ T-cell responses and the cytotoxic T lymphocyte (CTL) response, which ultimately lead to lysis of tumor cells.

GV1001 is an MHC class II-restricted hTERT peptide vaccine, which consists of amino acids 611-626 of the hTERT active site. Granulocyte-monocyte colonystimulating factor (GM-CSF) and Toll-like receptor-7 (TLR-7) have been used as adjuvants in the GV1001 vaccine to eliminate the problem of self-tolerance. Preclinical studies in B-CLL patients confirmed that telomerase-positive leukemic cells can naturally induce telomerase-specific $\mathrm{T}$ cells [70]. However, a recent randomized phase III clinical trials reported that combining GV1001 to gemcitabine and capecitabine did not improve the overall survival of patients with locally advanced or metastatic pancreatic cancer [71].

Another vaccine, $\mathrm{Vx}-001$, consists of a cryptic peptide of hTERT or its optimized version with a modified tyrosine (Y1) residue at the first amino-acid and enhanced peptide affinity. The efficacy and safety of $\mathrm{Vx}-001$ has been confirmed in mouse model and in phase I/II clinical

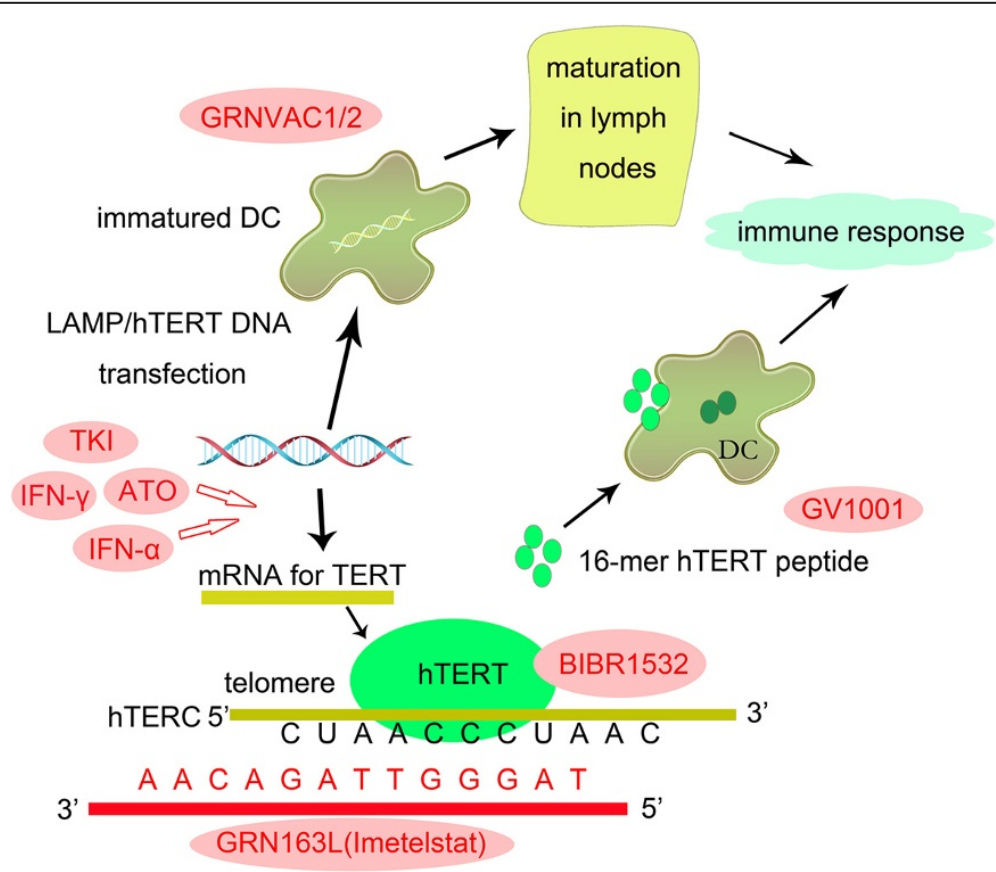

Figure 3 Telomerase inhibition therapies utilized in the treatment of hematologic malignancies. Telomerase-based immunotherapies utilize telomerase-associated antigens to produce an immune response which ultimately leads to lysis of tumor cells. Tyrosine kinase inhibitors (TKI), arsenic trioxide (ATO), interferon alpha (IFN-a) and interferon gamma (IFN- $\gamma$ ) reduce the expression of hTERT; imetelstat (GRN163) is complementary to the template region of the telomerase RNA component hTERC, competitively binding and blocking telomerase; BIBR1532 inhibits the specific active site of hTERT. 
trials in patients with various types of tumors. This vaccine is now scheduled for testing in a phase III clinical trial in NSCLC patients [72-74].

GRNVAC1 is a dendritic cell (DC) -based telomeraseassociated vaccine. Immature DCs are mobilized and isolated from the patient's own peripheral blood then transduced with mRNAs encoding the full-length hTERT protein in vitro. The lysosome-associated membrane protein (LAMP-1) mRNA sequence is co-transduced into DCs to make the antigen easily degradable and to enhance the immune response [75]. GRNVAC1 was tested in a randomized phase II clinical trial in patients with AML. Prolonged vaccination (up to 32 administrations) of GRNVAC1 in AML patients was well tolerated in most patients, and produced a greater effect in AML patients at high risk of relapse [76,77].

\section{Antisense oligonucleotide}

GRN163L (Imetelstat) is the most promising oligonucleotide possessing the ability to block telomerase by acting as a complementary sequence to hTERC. In an in vitro study, GRN163L showed effective inhibition of telomerase and of cell growth in B-CLL cells and tumor initiating B cells of patients with multiple myeloma (MM) $[78,79]$. GRN163L has been entered into stage I and II clinical trials in patients with refractory and relapsed MM and some types of solid tumors. GRN163L was reported to be generally well-tolerated in patients with relapsed and refractory MM. The most common treatment-related event was thrombocytopenia and prolongation of the activated partial thromboplastin time (APTT). The most marked hematologic toxicity was observed in two patients with prior auto-HSCT [80]. That may have been due to blockage of telomerase activity in HSCs which impaired reconstitution of the hematologic system. In a recent single-center study, GRN163L was shown to be effective in inducing morphologic and molecular remissions in patients with myelofibrosis, with a response rate of $44 \%$ [81].

\section{BIBR1532}

BIBR1532 is a synthetic non-nucleotidic small molecule which selectively inhibits the active site of telomerase. BIBR1532 leads to progressive telomere shortening and apoptotic cell death in a concentration-dependent manner in AML cell lines as well as in primary cells from patients with AML or CLL [82-84]. BIBR1532 inhibits the activity of telomerase through transcriptional suppression of survivin-mediated c-Myc and hTERT expression, increasing p73 and p21 expression, up-regulating the Bax/Bcl-2 molecular ratio and finally increasing P53-induced apoptosis $[84,85]$. P53 is the final executant of the telomeraseinhibiting effect of BIBR1532. In P53-negative K562 cells, the telomere length was stabilized when it reached approximately $5 \mathrm{~kb}[85]$.

\section{Other drugs with telomerase inhibiting activity}

IM (Gleevec), the first selective tyrosine kinase inhibitors (TKI), is reported to cause a dose-dependent inhibition of telomerase activity in various leukemia cell lines, including BCR-ABL negative cell lines [86-88]. IM regulates telomerase activity by decreasing the expression of hTERT and increasing the expression of telomerase inhibitor protein phosphatase 2A (PP2A) [87]. Following treatment with IM, the expression levels of TRF1, TRF2 and PinX1 are markedly reduced. The second-generation TKIs nilotinib and dasatinib, which have higher potency than imatinib against BCR-ABL (reviewed by Wei et al.), are more effective in reducing telomerase activity $[89,90]$.

Arsenic trioxide (ATO) is successfully used to induce complete remission and to trigger apoptotic death of APL cells [91,92]. Ghaffari et al. reported a dose-dependent inhibition of telomerase activity of ATO and a reduction in telomere length in ATO-treated NB4 cells. The mRNA levels of Pin1, survivin, c-Myc, hTERT, and PinX1 were all reduced in a concentration-dependent manner after 2 days of ATO treatment [93].

Interferons (IFNs) are multi-functional cytokines produced by eukaryotic cells. Xu et al. reported that IFN- $\alpha$ could significantly down-regulate the expression of hTERT and the activity of telomerase in many types of human hematologic malignant cell lines, primary leukemic cells and T-lymphocytes within 4 hours of treatment at a concentration of $5000 \mathrm{U} / \mathrm{mL}$, through suppressing the hTERT promoter activity [94]. Lindkvist et al. reported that IFN- $\gamma$ could also induce a decrease of hTERT expression. hTERT mRNA levels were virtually abolished after $48 \mathrm{~h}$ of IFN- $\gamma$ treatment at $5000 \mathrm{U} / \mathrm{mL}$ [95].

\section{Conclusions}

Telomeres are essential for the maintenance of chromosome stability in mammalian cells. Accelerated telomere shortening leads to activation of telomerase in stem cells and in the majority of tumor cells. In patients with hematologic malignancies, shortened telomeres and increased telomerase activity are usually observed and are associated with disease progression. In patients who have received HSCT the telomere length of engrafted stem cells is closely related to the outcomes of HSCT. Consequently the telomere characteristics should be taken into consideration during donor selection. It is also necessary to evaluate the effect of chemotherapy and conditioning courses on telomere length. Many promising telomerase targeting therapies have been confirmed to be tolerable and efficient to induce immune responeses in patients with hematological malignancies. However optimized strategies are still required to ensure their clinical efficiency. Further work will be needed to elucidate the complete story of telomere biology and to explore efficient telomerase-targeting therapies in hematologic malignances. 


\section{Abbreviations}

ATM: Ataxia telangiectasia-mutated gene; ATR: Ataxia telangiectasia and Rad3; ALT: Alternative lengthening of telomeres; sS DNA: Single-strand DNA; ds DNA: Double-strand DNA; TRF1: Telomeric repeat-binding factors 1; TRF2: Telomeric repeat-binding factors 2; TIN2: TRF1-interacting nuclear factor 2; Rap1: TRF2-interacting protein 1; POT1: Protection of telomeres protein 1; TPP1: POT1 and TIN2-interacting protein 1; AL: Acute leukemia; AML: Acute myeloid leukemia; ALL: Acute lymphoblastic leukemia; LDH: Lactate dehydrogenase; CR: Complete remission; APL: Acute promyelocytic leukemia; CLL: Chronic lymphocytic leukemia; UMIGVH: Unmutated immunoglobulin variable region; PFS: Progression-free survival; OS: Overall survival; CML: Chronic myelocytic leukemia; CP: Chronic phase; BP: Blastic phase; CCR: Completely cytogenetic remission; IM: Imatinib Mesylate; ECTR: Extra-chromosomal telomeric repeat; AP: Accelerated phase; MDS: Myelodysplastic syndromes; IPSS: International Prognostic Score System; 3D: Three-dimensional; HSCT: Hematopoietic stem cell transplantation; HSCs: Hematopoietic stem cells; auto-HSCT: Autologous hematopoietic stem cell transplantation; allo-HSCT: Allogeneic hematopoietic stem cell transplantation; GVHD: Graft-versus-host disease; CGVHD: Chronic graft-versus-host disease; aGVHD: Acute graft-versus-host disease; Treg: Regulatory T cells; PBSCs: Peripheral blood progenitor cells; t-MDS/AML: Therapy-related myelodysplasia or acute myelogenous leukemia; CTL: Cytotoxic T lymphocyte; GM-CSF: Granulocyte-monocyte colony-stimulating factor; TLR-7: Toll-like receptor-7; DC: Dendritic cell; MM: Multiple myeloma; APTT: Activated partial thromboplastin time; TKI: Tyrosine kinase inhibitors; PP2A: Protein phosphatase 2A: ATO: Arsenic trioxide.

\section{Competing interests}

The authors declare no conflict of interest.

\section{Authors' contributions}

LW participated in the design of this review, performed the selection and interpretation of data, and drafted the manuscript. HX participated in the design of this review, helped to draft and revise the manuscript. XZ performed the selection and interpretation of information about acute leukemia and helped to draft the manuscript. CW performed the selection and interpretation of information about the telomere biology and helped to draft the manuscript. $\mathrm{HH}$ conceived of the review, and participated in its design and coordination and revised the manuscript. All authors read and approved the final manuscript.

\section{Acknowledgements}

The work was funded by the Key Project of the National Natural Science Foundation of China (81230014), the National High Technology Research and Development Program of China (2012AA020905), the National Natural Science Foundation of China $(81100387,81170501)$ and the Major Technology Program (Key Social Development) of the Science Technology Department of Zhejiang Province (2012C13021-1).

\section{Author details \\ 'Bone Marrow Transplantation Center, The First Affiliated Hospital, Zhejiang University, School of Medicine, No. 79 Qingchun Rd, Hangzhou 310003, Zhejiang Province, P R China. ${ }^{2}$ Department of Haematology, Guangzhou Liuhuagiao Hospital, Guangzhou, Guangdong Province, P R China. ${ }^{3}$ Department of Haematology, The First Affiliated Hospital, Zhengzhou University, Zhengzhou, Henan Province, P R China.}

Received: 10 June 2014 Accepted: 6 August 2014

Published: 20 August 2014

\section{References}

1. Blackburn EH: Structure and function of telomeres. Nature 1991, 350:569-573.

2. Griffith JD, Comeau L, Rosenfield S, Stansel RM, Bianchi A, Moss H, de Lange $\mathrm{T}$ : Mammalian telomeres end in a large duplex loop. Cell 1999, 97:503-504.

3. Olovnikov AM: A theory of marginotomy. The incomplete copying of template margin in enzymic synthesis of polynucleotides and biological significance of the phenomenon. J Theor Biol 1973, 41:181-190.

4. Harley $C B$, Futcher $A B$, Greider CW: Telomeres shorten during ageing of human fibroblasts. Nature 1990, 345:458-460.
5. Takai H, Smogorzewska A, de Lange T: DNA damage foci at dysfunctional telomeres. Curr Biol 2003, 13:1549-1556.

6. Shay JW, Bacchetti S: A survey of telomerase activity in human cancer. Eur J Cancer 1997, 33:787-791.

7. Bryan TM, Englezou A, Dalla-Pozza L, Dunham MA, Reddel RR: Evidence for an alternative mechanism for maintaining telomere length in human tumors and tumor-derived cell lines. Nat Med 1997, 3:1271-1274.

8. Greider CW, Blackburn EH: A telomeric sequence in the RNA of Tetrahymena telomerase required for telomere repeat synthesis. Nature 1989, 337:331-337.

9. Feng J, Funk WD, Wang SS, Weinrich SL, Avilion AA, Chiu CP, Adams RR, Chang E, Allsopp RC, Yu J: The RNA component of human telomerase. Science 1995, 269:1236-1241.

10. de Lange T: Shelterin: the protein complex that shapes and safeguards human telomeres. Genes Dev 2005, 19:2100-2110.

11. Arat NÖ, Griffith JD: Human Rap1 interacts directly with telomeric DNA and regulates TRF2 localization at the telomere. J Biol Chem 2012, 287:41583-41594.

12. Chen $Y$, Yang $Y$, van Overbeek $M$, Donigian JR, Baciu $P$, de Lange $T$, Lei $M: A$ shared docking motif in TRF1 and TRF2 used for differential recruitment of telomeric proteins. Science 2008, 319:1092-1096.

13. Ye JZ, Donigian JR, van Overbeek M, Loayza D, Luo Y, Krutchinsky AN, Chait BT, de Lange T: TIN2 binds TRF1 and TRF2 simultaneously and stabilizes the TRF2 complex on telomeres. J Biol Chem 2004, 279:47264-47271.

14. Kendellen MF, Barrientos KS, Counter CM: POT1 association with TRF2 regulates telomere length. Mol Cell Biol 2009, 29:5611-5619.

15. Denchi EL, de Lange T: Protection of telomeres through independent control of ATM and ATR by TRF2 and POT1. Nature 2007, 448:1068-1071.

16. Wang $Y$, Shen MF, Chang S: Essential roles for Pot1b in HSC self-renewal and survival. Blood 2011, 118:6068-6077.

17. Ye JZ, Hockemeyer D, Krutchinsky AN, Loayza D, Hooper SM, Chait BT, de Lange T: POT1-interacting protein PIP1: a telomere length regulator that recruits POT1 to the TIN2/TRF1 complex. Genes Dev 2004, 18:1649-1654.

18. Nandakumar J, Bell CF, Weidenfeld I, Zaug AJ, Leinwand LA, Cech TR: The TEL patch of telomere protein TPP1 mediates telomerase recruitment and processivity. Nature 2012, 492:285-289.

19. Capraro V, Zane L, Poncet D, Perol D, Galia P, Preudhomme C, BonnefoyBerard N, Gilson E, Thomas X, El-Hamri M, Chelghoun Y, Michallet M, Wattel E, Mortreux F, Sibon D: Telomere deregulations possess cytogenetic, phenotype, and prognostic specificities in acute leukemias. Exp Hematol 2011, 39:195-202.e2

20. Asfour IA, Fayek MH, El-Kourashy SA, Youssef SR, El-Gohary GM, Mohamed OF: Correlation of telomerase activity to apoptosis and survival in adult acute lymphoblastic leukemia: an Egyptian single-center study. Ann Hematol 2008, 87:213-221.

21. Wang $Y$, Fang $M$, Sun $X$, Sun J: Telomerase activity and telomere length in acute leukemia: correlations with disease progression, subtypes and overall survival. Int J Lab Hematol 2010, 32:230-238.

22. Ohyashiki JH, Ohyashiki K, Iwama H, Hayashi S, Toyama K, Shay JW: Clinical implications of telomerase activity levels in acute leukemia. Clin Cancer Res 1997, 3:619-625.

23. Shi JM, Huang $H$, Chen QF, Lin MF: A study of the relationship between expression level of TRF1 protein and telomerase activity in human acute leukemia. J Zhejiang Univ Sci B 2006, 7:154-158.

24. Ohyashiki JH, Hayashi S, Yahata N, Iwama H, Ando K, Tauchi T, Ohyashiki K: Impaired telomere regulation mechanism by TRF1 (telomere-binding protein), but not TRF2 expression, in acute leukemia cells. Int J Oncol 2001, 18:593-598.

25. Yamada K, Yagihashi A, Yamada M, Asanuma K, Moriai R, Kobayashi D, Tsuji N, Watanabe N: Decreased gene expression for telomeric-repeat binding factors and TIN2 in malignant hematopoietic cells. Anticancer Res 2002, 22:1315-1320.

26. Kipps TJ: Chronic lymphocytic leukemia. Curr Opin Hematol 2000, 7:223-234.

27. Véronèse $L$, Tournilhac $O$, Callanan $M$, Prie $N$, Kwiatkowski $F$, Combes $P$, Chauvet M, Davi F, Gouas L, Verrelle P, Guièze R, Vago P, Bay JO, Tchirkov A: Telomeres and chromosomal instability in chronic lymphocytic leukemia. Leukemia 2013, 27:490-493.

28. Britt-Compton B, Lin TT, Ahmed G, Weston V, Jones RE, Fegan C, Oscier DG, Stankovic T, Pepper C, Baird DM: Extreme telomere erosion in ATM-mutated and 11q-deleted CLL patients is independent of disease stage. Leukemia 2012, 26:826-830. 
29. Roos G, Kröber A, Grabowski P, Kienle D, Bühler A, Döhner H, Rosenquist R, Stilgenbauer S: Short telomeres are associated with genetic complexity, high-risk genomic aberrations, and short survival in chronic lymphocytic leukemia. Blood 2008, 111:2246-2252.

30. Pozzo F, Dalbo M, Peragine N, Bomben R, Zucchetto A, Rossi F, Degan M, Rossi D, Chiarenza A, Grossi A, Di Raimondo F, Zaja F, Pozzato G, Secchiero P, Gaidano G, Del Poeta G, Zauli G, Fo ÀR, Guarini A, Gattei V: Detection of TP53 dysfunction in chronic lymphocytic leukemia by an in vitro functional assay based on TP53 activation by the non-genotoxic drug Nutlin-3: a proposal for clinical application. J Hematol Oncol 2013, 6:83

31. Sellmann $L$, de Beer $D$, Bartels $M$, Opalka B, Nückel $H$, Dührsen U, Dürig J, Seifert M, Siemer D, Küppers R, Baerlocher GM, Röth A: Telomeres and prognosis in patients with chronic lymphocytic leukaemia. Int J Hematol 2011, 93:74-82.

32. Counter CM, Gupta J, Harley CB, Leber B, Bacchetti S: Telomerase activity in normal leukocytes and in hematologic malignancies. Blood 1995, 85:2315-2320

33. Poncet $D$, Belleville A, t'kint de Roodenbeke C, Roborel de Climens A, Simon B, Callet-Bauchu E, Salles G, Sabatier L, Delic J, Gilson E: Changes in the expression of telomere maintenance genes suggest global telomere dysfunction in B-chronic lymphocytic leukemia. Blood 2008, 111:2388-2391.

34. Capraro V, Zane L, Poncet D, Perol D, Galia P, Preudhomme C, Bonnefoy-Berard N, Gilson E, Thomas X, El-Hamri M, Chelghoun Y, Michallet M, Wattel E, Mortreux F, Sibon D: Telomeric damage in early stage of chronic lymphocytic leukemia correlates with shelterin dysregulation. Blood 2011, 118:1316-1322.

35. Ramsay AJ, Quesada V, Foronda M, Conde L, Martínez-Trillos A, Villamor N, Rodríguez D, Kwarciak A, Garabaya C, Gallardo M, López-Guerra M, López-Guillermo A, Puente XS, Blasco MA, Campo E, López-Otín C: POT1 mutations cause telomere dysfunction in chronic lymphocytic leukemia. Nat Genet 2013, 45:526-530.

36. Sattler M, Verma S, Shrikhande G, Byrne CH, Pride YB, Winkler T, Greenfield $E A$, Salgia $R$, Griffin JD: The BCR/ABL tyrosine kinase induces production of reactive oxygen species in hematopoietic cells. J Biol Chem 2000, 275:24273-24278.

37. Brummendorf $T H$, Holyoake TL, Rufer N, Barnett MJ, Schulzer M, Eaves CJ, Eaves AC, Lansdorp PM: Prognostic implications of differences in telomere length between normal and malignant cells from patients with chronic myeloid leukemiameasured by flow cytometry. Blood 2000, 95:1883-1890.

38. Drummond M, Lennard A, Brûmmendorf T, Holyoake T: Telomere shortening correlates with prognostic score at diagnosis and proceeds rapidly during progression of chronic myeloid leukemia. Leuk Lymphoma 2004, 45:1775-1781.

39. Braig M, Pällmann N, Preukschas M, Steinemann D, Hofmann W, Gompf A, Streichert T, Braunschweig T, Copland M, Rudolph KL, Bokemeyer C, Koschmieder S, Schuppert A, Balabanov S, Brümmendorf TH: A 'telomereassociated secretory phenotype' cooperates with BCR-ABL to drive malignant proliferation of leukemic cells. Leukemia, in press.

40. Bakalova R, Ohba H, Zhelev Z, Kubo T, Fujii M, Ishikawa M, Shinohara Y, Baba Y: Antisense inhibition of Bcr-Abl/c-Abl synthesis promotes telomerase activity and upregulates tankyrase in human leukemia cells. FEBS Lett 2004, 564:73-84.

41. Samassekou O, Li H, Hébert J, Ntwari A, Wang H, Cliché CG, Bouchard E, Huang S, Yan J: Chromosome arm-specific long telomeres: a new clonal event in primary chronic myelogenous leukemia cells. Neoplasia 2011, 13:550-560.

42. Samassekou O, Ntwari A, Hébert J, Yan J: Individual Telomere Lengths in Chronic Myeloid Leukemia. Neoplasia 2009, 11:1146-1154.

43. Samassekou O, Malina A, Hébert J, Yan J: Presence of alternative lengthening of telomeres associated circular extrachromosome telomere repeats in primary leukemia cells of chronic myeloid leukemia. $J$ Hematol Oncol 2013, 6:26.

44. Campbell L, Fidler C, Eagleton H, Peniket A, Kusec R, Gal S, Littlewood TJ, Wainscoat JS, Boultwood J: hTERT, the catalytic component of telomerase, is downregulated in the haematopoietic stem cells of patients with chronic myeloid leukaemia. Leukemia 2006, 20:671-679.

45. Bennett JM, Catovsky D, Daniel MT, Flandrin G, Galton DA, Gralnick HR, Sultan C: Proposals for the classification of the myelodysplastic syndromes. Br J Haematol 1982, 51:189-199.
46. Rollison DE, Epling-Burnette PK, Park JY, Lee JH, Park H, Jonathan K, Cole AL, Painter JS, Guerrier M, Meléndez-Santiago J, Fulp W, Komrokji R, Lancet J, List AF: Telomere length in myelodysplastic syndromes. Leuk Lymphoma 2011, 52:1528-1536.

47. Yang L, Mailloux A, Rollison DE, Painter JS, Maciejewski J, Paquette RL, Loughran TP, McGraw K, Makishima H, Radhakrishnan R, Wei S, Ren X, Komrokji R, List AF, Epling-Burnette PK: Naive T-cells in myelodysplastic syndrome display intrinsic human telomerase reverse transcriptase (hTERT) deficiency. Leukemia 2013, 27:897-906.

48. Marcondes AM, Bair S, Rabinovitch PS, Gooley T, Deeg HJ, Risques R: No telomere shortening in marrow stroma from patients with MDS. Ann Hematol 2009, 88:623-628.

49. Lange K, Holm L, Vang Nielsen K, Hahn A, Hofmann W, Kreipe H, Schlegelberger B, Göhring G: Telomere shortening and chromosomal instability in myelodysplastic syndromes. Gene Chromosome Canc 2010, 49:260-269.

50. Ohyashiki JH, Ohyashiki K, Fujimura T, Kawakubo K, Shimamoto T, Iwabuchi A, Toyama K: Telomere shortening associated with disease evolution patterns in myelodysplastic syndromes. Cancer Res 1994, 54:3557-3560.

51. Ohyashiki JH, Iwama H, Yahata N, Ando K, Hayashi S, Shay JW, Ohyashiki K: Telomere stability is frequently impaired in high-risk groups of patients with myelodysplastic syndromes. Clin Cancer Res 1999, 5:1155-1160.

52. Sieglová Z, Zilovcová S, Cermák J, Ríhová H, Brezinová D, Dvoráková R, Marková M, Maaloufová J, Sajdová J, Brezinová J, Zemanová Z, Michalová K: Dynamics of telomere erosion and its association with genome instability in myelodysplastic syndromes (MDS) and acute myelogenous leukemia arising from MDS: a marker of disease prognosis? Leuk Res 2004, 28:1013-1021.

53. Briatore F, Barrera G, Pizzimenti S, Toaldo C, Casa CD, Laurora S, Pettazzoni P, Dianzani MU, Ferrero D: Increase of telomerase activity and hTERT expression in myelodysplastic syndromes. Cancer Biol Ther 2009, 8:883-889.

54. Gadji M, Adebayo Awe J, Rodrigues P, Kumar R, Houston DS, Klewes L, Dièye TN, Rego EM, Passetto RF, de Oliveira FM, Mai S: Profiling three-dimensional nuclear telomeric architecture of myelodysplastic syndromes and acute myeloid leukemia defines patient subgroups. Clin Cancer Res 2012, 18:3293-3304.

55. Vaziri H, Dragowska W, Allsopp RC, Thomas TE, Harley CB, Lansdorp PM: Evidence for a mitotic clock in human hematopoietic stem cells: loss of telomeric DNA with age. Proc Natl Acad Sci U S A 1994, 91:9857-9860.

56. Engelhardt M, Kumar R, Albanell J, Pettengell R, Han W, Moore MA: Telomerase regulation, cell cycle, and telomere stability in primitive hematopoietic cells. Blood 1997, 90:182-193.

57. Sekulovic S, Gylfadottir V, Vulto I, Gasparetto M, Even Y, Brookes C, Smith C, Eaves CJ, Lansdorp PM, Rossi FM, Humphries RK: Prolonged self-renewal activity unmasks telomerase control of telomere homeostasis and function of mouse hemopoietic stem cells. Blood 2011, 118:1766-1773.

58. Blasco MA, Lee HW, Hande MP, Samper E, Lansdorp PM, DePinho RA, Greider CW: Telomere shortening and tumor formation by mouse cells lacking telomerase RNA. Cell 1997, 91:25-34.

59. Ju Z, Jiang H, Jaworski M, Rathinam C, Gompf A, Klein C, Trumpp A, Rudolph KL: Telomere dysfunction induces environmental alterations limiting hematopoietic stem cell function and engraftment. Nat Med 2007, 13:742-747.

60. Akiyama M, Asai O, Kuraishi Y, Urashima M, Hoshi Y, Sakamaki H, Yabe H, Furukawa T, Yamada O, Mizoguchi H, Yamada $\mathrm{H}$ : Shortening of telomere in recipients of both autologous and allogeneic hematopoietic stem cell transplantation. Bone Marrow Transplant 2000, 25:441-447.

61. Baerlocher GM, Rovó A, Müller A, Matthey S, Stern M, Halter J, Heim D, Rischewski J, Gratwohl A, Tichelli A: Cellular senescence of white blood cells in very long-term survivors after allogeneic hematopoietic stem cell transplantation: the role of chronic graft-versus-host disease and female donor sex. Blood 2009, 114:219-222.

62. Rufer N, Brümmendorf TH, Chapuis B, Helg C, Lansdorp PM, Roosnek E: Accelerated telomere shortening in hematological lineages is limited to the first year following stem cell transplantation. Blood 2001, 97:575-577.

63. Imanishi T, Hano T, Nishio I: Estrogen reduces endothelial progenitor cell senescence through augmentation of telomerase activity. $J$ Hypertens 2005, 23:1699-1706.

64. Kawano Y, Kim HT, Matsuoka K, Bascug G, McDonough S, Ho VT, Cutler C, Koreth J, Alyea EP, Antin JH, Soiffer RJ, Ritz J: Low telomerase activity in CD4+ regulatory $T$ cells in patients with severe chronic GVHD after hematopoietic stem cell transplantation. Blood 2011, 118:5021-5030. 
65. Ricca I, Compagno M, Ladetto $M$, Rocci $A$, Dell'Aquila $M$, Omedè $P$, De Marco F, D'Antico S, Caracciolo D, Ferrero D, Carlo-Stella C, Tarella C: Marked telomere shortening in mobilized peripheral blood progenitor cells (PBPC) following two tightly-spaced high-dose chemotherapy courses with G-CSF. Leukemia 2005, 19:644-651

66. Ruella M, Rocci A, Ricca I, Carniti C, Bodoni CL, Ladetto M, Caracciolo D, Boccadoro M, Carlo-Stella C, Corradini P, Tarella C: Comparative assessment of telomere length before and after hematopoietic SCT: role of grafted cells in determining post-transplant telomere status. Bone Marrow Transplant 2010, 45:505-512.

67. Mangerini R, Lanino E, Terranova P, Faraci M, Pistillo MP, Gaetani GF, Ferraris AM: Telomere length of donors influences granulocyte recovery in children after hematopoietic stem cell transplantation. Ann Hematol 2009, 88:1029-1031.

68. Chakraborty S, Sun CL, Francisco L, Sabado M, Li L, Chang KL, Forman S, Bhatia S, Bhatia R: Accelerated telomere shortening precedes development of therapy-related myelodysplasia or acute myelogenous leukemia after autologous transplantation for lymphoma. J Clin Oncol 2009, 27:791-798.

69. Peffault de Latour R, Calado RT, Busson M, Abrams J, Adoui N, Robin M, Larghero J, Dhedin N, Xhaard A, Clave E, Charron D, Toubert A, Loiseau P, Socié G, Young NS: Age-adjusted recipient pretransplantation telomere length and treatment-related mortality after hematopoietic stem cell transplantation. Blood 2012, 120:3353-3359.

70. Kokhaei P, Palma M, Hansson L, Osterborg A, Mellstedt H, Choudhury A: Telomerase (hTERT 611-626) serves as a tumor antigen in B-cell chronic lymphocytic leukemia and generates spontaneously antileukemic, cytotoxic T cells. Exp Hematol 2007, 35:297-304

71. Middleton G, Silcocks P, Cox T, Valle J, Wadsley J, Propper D, Coxon F, Ross P, Madhusudan S, Roques T, Cunningham D, Falk S, Wadd N, Harrison M, Corrie P, Iveson T, Robinson A, McAdam K, Eatock M, Evans J, Archer C, Hickish T, Garcia-Alonso A, Nicolson M, Steward W, Anthoney A, Greenhalf W, Shaw V, Costello E, Naisbitt D, Rawcliffe C, Nanson G, Neoptolemos J: Gemcitabine and capecitabine with or without telomerase peptide vaccine GV1001 in patients with locally advanced or metastatic pancreatic cancer (TeloVac): an open-label, randomised, phase 3 trial. Lancet Oncol 2014, 15:829-840.

72. Georgoulias V, Douillard JY, Khayat D, Manegold C, Rosell R, Rossi A, MenezJamet J, Iché M, Kosmatopoulos K, Gridelli C: A multicenter randomized phase Ilb efficacy study of Vx-001, a peptide-based cancer vaccine as maintenance treatment in advanced non-small-cell lung cancer: treatment rationale and protocol dynamics. Clin Lung Cancer 2013, 14:461-465

73. Kotsakis A, Vetsika EK, Christou S, Hatzidaki D, Vardakis N, Aggouraki D, Konsolakis G, Georgoulias V, Christophyllakis C, Cordopatis P, Kosmatopoulos K, Mavroudis D: Clinical outcome of patients with various advanced cancer types vaccinated with an optimized cryptic human telomerase reverse transcriptase (TERT) peptide: results of an expanded phase II study. Ann Oncol 2012, 23:442-449.

74. Bolonaki I, Kotsakis A, Papadimitraki E, Aggouraki D, Konsolakis G, Vagia A, Christophylakis C, Nikoloudi I, Magganas E, Galanis A, Cordopatis P, Kosmatopoulos K, Georgoulias V, Mavroudis D: Vaccination of patients with advanced non-small-cell lung cancer with an optimized cryptic human telomerase reverse transcriptase peptide. J Clin Oncol 2007, 25:2727-2734.

75. Su Z, Vieweg J, Weizer AZ, Dahm P, Yancey D, Turaga V, Higgins J, Boczkowsk D, Gilboa E, Dannull J: Enhanced induction of telomerase-specific CD4(+) T cells using dendritic cells transfected with RNA encoding a chimeric gene product. Cancer Res 2002, 62:5041-5048.

76. DiPersio JF, Collins RH Jr, Blum W, Devetten MP, Stiff P, Elias L, Reddy A, Smith $J A$, Khoury HJ: Immune responses in AML patients following vaccination with GRNVAC1, autologous RNA transfected dendritic cells expressing telomerase catalytic subunit hTERT [abstract]. Blood 2009, 114:633.

77. Khoury HJ, Collins RH Jr, Blum W, Maness L, Stiff P, Kelsey SM, Reddy A, Smith JA, DiPersio JF: Prolonged administration of the telomerase vaccine GRNVAC1 is well tolerated and appears to be associated with favorable outcomes in high-risk acute myeloid leukemia (AML) [abstract]. Blood 2010, 116:2190.

78. Lin C, Damle RN, Chiorazzi N, Chin AC: GRN163L inhibits telomerase activity in B-CLL cells [Abstract]. Blood 2005, 106:5041.

79. Brennan SK, Wang Q, Tressler R, Harley C, Go N, Bassett E, Huff CA, Jones RJ, Matsui W: Telomerase inhibition targets clonogenic multiple myeloma cells through telomere length-dependent and independent mechanisms. Plos ONE 2010, 5:e12487.
80. Chanan-Khan AA, Munshi NC, Hussein MA, Elias L, Benedetti F, Smith J, Khor SP, Huff CA: Results of a phase I study of GRN163L, a direct inhibitor of telomerase, in patients with relapsed and refractory multiple myeloma (MM). Blood 2008, 112:1263.

81. Tefferi A, Begna K, Laborde RR, Patnaik MM, Lasho TL, Zblewski D, Finke C, Schimek L, LaPlant BR, Hanson CA, Stuart MJ, Pardanani A: Imetelstat, a telomerase inhibitor, induces morphologic and molecular remissions in Myelofibrosis and reversal of bone marrow fibrosis [Abstract]. Blood 2013, 122:662.

82. Bashash D, Ghaffari SH, Zaker F, Kazerani M, Hezave K, Hassani S, Rostami M, Alimoghaddam K, Ghavamzadeh A: BIBR1532 increases arsenic trioxidemediated apoptosis in acute promyelocytic leukemia cells: therapeutic potential for APL. Anticancer Agents Med Chem 2013, 13:1115-1125.

83. Bashash D, Ghaffari SH, Mirzaee R, Alimoghaddam K, Ghavamzadeh A: Telomerase inhibition by non-nucleosidic compound BIBR1532 causes rapid cell death in pre-B acute lymphoblastic leukemia cells. Leuk Lymphoma 2013, 54:561-568.

84. Bashash D, Ghaffari SH, Zaker F, Hezave K, Kazerani M, Ghavamzadeh A, Alimoghaddam K, Mosavi SA, Gharehbaghian A, Vossough P: Direct short-term cytotoxic effects of BIBR 1532 on acute promyelocytic leukemia cells through induction of p21 coupled with downregulation of c-Myc and hTERT transcription. Cancer Invest 2012, 30:57-64.

85. Brassat U, Balabanov S, Bali D, Dierlamm J, Braig M, Hartmann U, Sirma H, Günes C, Wege H, Fehse B, Gontarewicz A, Dikomey E, Borgmann K, Brümmendorf TH: Functional p53 is required for effective execution of telomerase inhibition in BCR-ABL-positive CML cells. Exp Hematol 2011, 39:66-76.

86. Chai JH, Zhang Y, Tan WH, Chng WJ, Li B, Wang X: Regulation of hTERT by BCR-ABL at multiple levels in K562 cells. BMC Cancer 2011, 11:512.

87. Uziel O, Fenig E, Nordenberg J, Beery E, Reshef H, Sandbank J, Birenbaum M, Bakhanashvili M, Yerushalmi R, Luria D, Lahav M: Imatinib mesylate (Gleevec) downregulates telomerase activity and inhibits proliferation in telomerase-expressing cell lines. Br J Cancer 2005, 92:1881-1891.

88. Mor-Tzuntz R, Uziel O, Shpilberg O, Lahav J, Raanani P, Bakhanashvili M, Rabizadeh E, Zimra Y, Lahav M, Granot G: Effect of imatinib on the signal transduction cascade regulating telomerase activity in K562 (BCR-ABL-positive) cells sensitive and resistant to imatinib. Exp Hematol 2010, 38:27-37.

89. Wei G, Rafiyath S, Liu D: First-line treatment for chronic myeloid leukemia: dasatinib, nilotinib, or imatinib. J Hematol Oncol 2010, 3:47.

90. Shapira S, Granot G, Mor-Tzuntz R, Raanani P, Uziel O, Lahav M, Shpilberg O: Second-generation tyrosine kinase inhibitors reduce telomerase activity in K562 cells. Cancer Lett 2012, 323:223-231.

91. Jing Y, Dai J, Chalmers-Redman RM, Tatton WG, Waxman S: Arsenic trioxide selectively induces acute promyelocytic leukemia cell apoptosis via a hydrogen peroxide-dependent pathway. Blood 1999, 94:2102-2111.

92. Yedjou C, Tchounwou P, Jenkins J, McMurray R: Basic mechanisms of arsenic trioxide (ATO)-induced apoptosis in human leukemia (HL-60) cells. J Hematol Oncol 2010, 3:28.

93. Ghaffari SH, Momeny M, Bashash D, Mirzaei R, Ghavamzadeh A, Alimoghaddam $\mathrm{K}$ : Cytotoxic effect of arsenic trioxide on acute promyelocytic leukemia cells through suppression of NFkbeta-dependent induction of hTERT due to down-regulation of Pin1 transcription. Hematology 2012, 17:198-206.

94. Xu D, Erickson S, Szeps M, Gruber A, Sangfelt O, Einhorn S, Pisa P, Grandér $D$ : Interferon alpha down-regulates telomerase reverse transcriptase and telomerase activity in human malignant and nonmalignant hematopoietic cells. Blood 2000, 96:4313-4318.

95. Lindkvist A, Ivarsson $K$, Jernberg-Wiklund $H$, Paulsson-Karlsson $Y$ : Interferon-induced sensitization to apoptosis is associated with repressed transcriptional activity of the hTERT promoter in multiple myeloma. Biochem Biophys Res Commun 2006, 341:1141-1148.

\section{doi:10.1186/s13045-014-0061-9}

Cite this article as: Wang et al:: The role of telomeres and telomerase in hematologic malignancies and hematopoietic stem cell transplantation. Journal of Hematology \& Oncology 2014 7:61. 